\title{
Phonetics Transcription in English Language Teaching (ELT): Implications for English Language Teachers
}

\author{
Teddy Fiktorius \\ SMA Bina Mulia Pontianak, Kalimantan Barat \\ Indonesia \\ fiktoriusteddy@yahoo.com
}

Citation: Fiktorius, T. (2020). Phonetics transcription in English language teaching (ELT): implications for English language teachers. Notion: Journal of Linguistics, Literature, and Culture, Vol 2(2), p. 58-63. DOI: http://doi.org/10.12928/notion.v2i2.2068

\begin{tabular}{l|l}
\hline \multicolumn{1}{c}{ Article Info } & \multicolumn{1}{c}{ ABSTRACT } \\
\hline $\begin{array}{l}\text { Article History } \\
\text { - Article Received }\end{array}$ & This paper is written through descriptive method or library research to discuss \\
$16^{\text {th }}$ April 2020 & the use of phonetic transcription in the teaching of English as a foreign \\
- Article Accepted & language (EFL) using the International Phonetic Alphabet (IPA). The first \\
$13^{\text {th }}$ October 2020 & part describes the theoretical framework of the transcription basics. Then, the \\
next part discusses the advantages of the phonetic transcription. This is & followed by an illustration of understanding basic speech sounds. Some ideas \\
Keywords & of preparing classroom materials using the IPA are addressed in the next \\
phonetic transcription & section. Finally, some solutions as well as recommendations are proposed and \\
International Phonetic Alphabet & justification of the researcher's position toward the use of phonics as an EFL \\
EFL literacy instruction & literacy instruction in ELT is presented.
\end{tabular}




\section{INTRODUCTION}

Today there is not much talk about phonics as an English as a Foreign Language (EFL) literacy instruction in English Language Teaching (ELT). According to Olugbeko[1], the single most important theoretical problem underlying the practical problem of teaching initial English literacy is understanding how the writing system relates to the spoken language. There are quite many reasons for integrating phonics into the adult education EFL curriculum. Pennington and Revell[2] claim that English spelling is morphophonemic, understanding how phonemes are represented by single letters as well as spelling patterns can assist in the development of basic ESL literacy.

This paper discusses the use of phonetic transcription in the teaching of English as a foreign language (EFL) using the International Phonetic Alphabet (IPA). English is the most widely taught language in the world and the IPA is the most widely used alphabet for phonetic transcription. Hosseinzadeh, Kambuziya, and Shariati[3] point out that phonetic transcription is nothing more than a written record of the sounds of a spoken language. The relationship between phonetic transcription and spoken language is very similar. Meanwhile, Tench[4] explains that transcription separates pronunciation from actual audio recording, and while this might at first seem to be counterproductive, in reality it has many advantages for teaching spoken language and pronunciation.

It is a great misfortune that phonics as an EFL literacy instruction has had very limited application in EFL teaching (as observed in the researcher's workplace). In the context of the researcher's workplace, where English is taught as a foreign language, the researcher has noticed that the English teachers do not pay much attention on phonics instruction in their daily teaching due to lack of professional development as well as conservative attitude of some teachers. In order not to be pessimistic though, the opportunity to apply this instruction into EFL teaching and learning is always open.

By carefully reviewing, analysing, and evaluating current literature and research on phonics instruction in enhancing the EFL teaching and learning, the researcher would advance his argument in this paper under some sections. The first part describes the theoretical framework of the basics of transcription. Then, the next part discusses the advantages of the phonetic transcription. This is followed by an illustration of understanding basic speech sounds. Some ideas of preparing classroom materials using the IPA are addressed in the section that follows. Finally, in the conclusion, the researcher proposes some solutions as well as some recommendations and justify his position toward the use of phonics as an EFL literacy instruction in ELT.

\section{The Basics of Transcription}

Transcribing spoken language phonetically is so straightforward that we simply write the phonetic symbols that correspond to the sounds we hear. It is not even necessary that we understand what we hear, as long as we can recognise sounds and transcribe them. The statement above is in line with Wells[5] who notes that it is certain that if we also understand the language, it is easier to recognise the sounds that are important. The IPA has hundreds of symbols, but fortunately only fifty or socorresponding to the number of sounds used in English-are necessary for transcription of English[6].

Fromkin, Rodman, \& Hyams[6] also add that there are two styles of transcription that we may find useful in EFL classes. The first is called narrow transcription: it is transcription that attempts to record every single phonological feature (sound) of an utterance, whether it is important to meaning or not. Narrow transcription is useful mainly when we are trying to show students their own foreign accents, or when we are contrasting accents of English or comparing pronunciation of English with pronunciation of other languages.

The second form of transcription is referred to as broad transcription. It documents only the sounds that are important to meaning. This type of transcription is also called phonemic. Broad transcription is used to show students how something should be pronounced. It emphasises only the sound differences that serve to distinguish meaning; tiny pronunciation features that merely betray a foreign or regional accent are not transcribed. Broad transcription is the type we would use in pronunciation keys, and indeed dictionaries use broad transcription to show the pronunciation of words[2]. 
The division between broad and narrow transcriptions is not precise. We can vary our transcription style anywhere between the two extremes as teaching requirements dictate. For example, in a broad transcription of English speech, we normally would not transcribe the length of vowels, because vowel length is unimportant to meaning in English. Changing a vowel from long to short or vice versa does not change the meaning of a word in which it occurs. We would transcribe vowel length in a narrow transcription, however, since the idea is to show exactly how something is pronounced in narrow transcription, including details that do not necessarily influence meaning. Nevertheless, we might still transcribe vowel length even in a broad transcription if we felt there were a need to do so in order to communicate a specific teaching point to our students. In other words, the amount of detail we include in our transcriptions is entirely up to us, and will usually be a function of the exact purpose for which we are using the transcription in class.

\section{Advantages of Phonetic Transcription}

One might ask what purpose phonetic transcription serves in English when the written form of English already represents the way the language is spoken. The following are some advantages of phonetic transcription.

Stabler[7] asserts that written English is only an approximate representation of the spoken language. Phonetic transcription, in contrast, is an exact representation, without any ambiguity, redundancy, or omission. In a phonetic transcription, every symbol stands for one sound, and one sound only. There are no "silent letters" nor are there any spoken sounds that are not represented in the transcription.

Next, a phonetic transcription can be used prescriptively to show students how a given word or phrase should be pronounced. Pennington and Revell[2] point out that the transcription can represent a precise, standard pronunciation, independent of the individual or regional accent of any teacher or audio recording. It thus allows students to see the correct pronunciation of an English word of phrase without the confusing influence of any anomalies in an instructor's speech, and provides a reliable, ideal model towards which students can work in their pronunciation, independently of the speech of any human instructor. Dictionaries use phonetic transcription in this way to indicate the standard pronunciation of words.

Furthermore, a phonetic transcription can be used diagnostically, to record and analyse the speech of students. Stabler[7] also explains that a student can often better understand his errors in pronunciation if he sees them laid out in static visual form. One might say that a picture is worth a thousand words, with transcription being the picture, and words being the spoken language. Students can compare transcriptions of their own speech to that of model speech and see and correct their mistakes.

In addition, phonetic transcription is useful for showing the significant differences between the pronunciation of isolated words in a dictionary and the actual pronunciation of those same words when they are grouped together in connected speech. Students can see why connected speech is more difficult to understand when they are shown the modifications in pronunciation that occur in such speech, and they can learn what modifications to expect and how to recognise them. They can also adopt a more natural-sounding speech themselves by noting the standard changes that occur in connected speech and emulating these themselves[8].

Finally, much time can be saved in many small ways by using transcription instead of audio recordings or "repeat after me" techniques. This view is supported by Pennington and Revell[2] who say that the correct pronunciation of a word can be indicated by simply writing its phonetic transcription on the whiteboard, instead of playing it over and over on a fuzzy-sounding cassette or repeating it over and over out loud for students. Features of pronunciation (stress, intonation, division into syllables, etc.) can be explained by showing them in transcriptions rather than trying to explain verbally.

\section{METHODOLOGY}

In the current research, descriptive method or library research is implemented to the problems of the research. This research is conducted by expressing the information from the available documents which is useful in the field of phonetic transcription in the teaching of English as a foreign language (EFL). 
The major aim of this research is to provide current information in the field of phonetics transcription in English language teaching (ELT) that will lead to promoting some insighful implications for English Language Teachers.

\section{RESULT AND DISCUSSION}

By having the explanation about the research gap above, the results of the research are described below.

\section{a. Understanding Basic Speech Sounds}

It is believed that EFL teachers already have an understanding of the main phonological concepts behind English and other languages, such as the notion of vowels, consonants, stress, and so on. Most of human speech is produced by forcing air from the lungs past the vocal cords in the larynx[5]. $\mathrm{He}$ also notes that the vocal cords are held under tension, and when air is forced between them, they vibrate, producing a buzzing noise that travels up the throat and out to the external world through the nose and mouth. The vocal tract (the parts of the nose and mouth and throat that participate in the production of speech sounds modifies this buzzing sound to produce vowels, consonants, and other features of speech.

\section{Vowels}

Wells[5] points out that vowels are sounds produced by modulating the buzzing noise from the vocal cords as it passes through the mouth and nose. The shape of the vocal tract is changed by changing the position of the tongue, jaw, lips, and velum (the mobile fleshy area at the upper rear of the mouth that can open or close the passage between mouth and nose). The sound is not obstructed when vowels are pronounced; instead, the shape of the vocal tract is adjusted, primarily through changes in the shape and position of the tongue, in order to reinforce certain frequencies of sound and absorb others. Many distinct vowels can be produced in this way.

Another characteristic of vowels is that they can be rounded or unrounded, where the rounding in question is the rounding of the lips when the vowel is pronounced. Gilakjani[9] claims that the IPA has separate vowel symbols for the rounded and unrounded vowels in most tongue positions. In English, most front vowels tend to be unrounded (/i//, /e/, / / /, /_/), and most back vowels tend to be rounded $(/ \mathrm{u} /, / \mathrm{o} /, / \mathrm{o} /)$, but this is just the idiosyncrasy of English, and some other languages do not follow this pattern.

Vowels can also vary in their duration. The duration of a vowel is not important to meaning in English, but English speakers tend to pronounce certain vowels long and others short. For example, the /i/ in pin usually has quite a short duration, whereas the $/ \mathrm{u} /$ in moon has quite a long duration. In narrow transcriptions, the length of the vowel is often explicitly transcribed, e.g., /mu_n/ for moon. In broad transcriptions, the length need not be transcribed, because it does not change meaning[9].

The sound of a vowel can reach the outside world either through the mouth or the nose, or through a combination of both. Pennington and Revell[2] assert that a vowel that exits primarily through the mouth is said to be oral, and a vowel that exists primarily through the nose is said to be nasal. In the IPA, a vowel is oral unless it is marked with a special diacritic indicating nasal pronunciation: thus, /a / is an oral vowel, and $/ \mathbf{a}^{\sim} /$ is its nasal equivalent. The difference between nasal and oral vowels is not important in

\section{Consonants}

According to Stabler[7], consonants may be broadly described as movements of the vocal tract that obstruct or restrict the flow of sound or air. In most languages, consonants alternate with vowels in speech, although it is not unusual to hear several consonants in succession in many languages (including English). Consonants typically produce sound by either completely obstructing the flow of air or sound from a preceding or following vowel, or by restricting the flow of sound or air so much that it becomes audible.

Consonants can also be considered voiced or unvoiced. A voiced consonant is one that is pronounced while the vocal cords are vibrating. An unvoiced consonant is one that is pronounced while the vocal cords are motionless. Many consonants are distinguished only by voicing; that is, they are distinguished only by the presence or absence of vibration in the vocal cords. For example, /p/ and $/ \mathrm{b} /$ are articulated in the same way, but the first is unvoiced, and the second is voiced, so they are separate consonants. The IPA uses separate symbols for voiced and unvoiced consonants. In many languages, including English, the difference between a voiced and an unvoiced consonant is important to 
meaning (pan is not the same as ban), and should always be transcribed[6].

\section{b. The Difference between Meaning and Sound}

A key concept that applies to English and all other languages is that of phonemes. It is vital to understanding what phonemes are in order to use phonetic transcription correctly.

Wells[5] explains that every language has a set of phones. Phones are sounds that can be consistently and individually distinguished in a spoken language, whether they mean anything or not. The number of phones in a language can be very large, but only a few of those phones have any influence on the actual meaning of speech. The phones that serve to distinguish between meanings are called phonemes, and they are much fewer in number than the complete set of phones. English has about 42 phonemes. The important thing to remember is this: In order to understand a language and be understood when speaking that language, a student must master all the phonemes of the language.

Wells[5] also notes that in order to state the definition of a phoneme another way, whenever any two sounds in a language are contrasted with each other to represent a difference in meaning, they are said to be phonemes. For example, the difference between the vowel /i/ in pin and the vowel /_/ in pan mark a difference in meaning between the two words, and so these vowel sounds are phonemes. And so, by extension, any difference in pronunciation that serves to distinguish meaning is said to be phonemic. The more frequently two sounds are contrasted in a language to distinguish meaning, the more phonemic they are. If two sounds are simply characteristic of a language, but are never used to distinguish one meaning from another, they are phones, but they are not phonemes.

The same principle applies to all phonemes of English. Tench[4] says that in transcription, we always transcribe phonemes, because the transcription is incomprehensible without them. We may or may not choose to transcribe other phones that are not phonemes, depending on the level of detail we want in the transcription; but we cannot omit the phonemes. The broadest transcriptions contain only phonemes and are thus often called phonemic transcriptions; the narrowest transcriptions contain the phonemes.

\section{c. Errors in Transcription}

Although the IPA is used around the world for thousands of different languages, it is not always used correctly. When we use the IPA to teach students, it is important to use the IPA in the most standard way possible in order to avoid conflict with the transcription of sounds in her own native language and/or the use of the IPA that they may have already learnt in other environments.

Unfortunately, many users of the IPA in English-particularly those who are native speakershave developed the habit of misusing some IPA symbols in a characteristic way that can seriously confuse students from other environments if they are exposed to it. Stabler[7] points out that some of these errors are attributable to the difficulty of typesetting the unusual symbols of the IPA (a difficulty largely eliminated today by computers); others are due to a fundamental misunderstanding of English phonetics.

\section{d. Preparing Classroom Materials Using the IPA}

Preparing handwritten classroom materials using the IPA poses no particular problems. This is made possible since we can write all the necessary symbols by hand. If we are using a computer to prepare our classroom materials, however, there are some special considerations we must keep in mind in order to use IPA symbols in our documents. There are several options for including IPA transcriptions in documents prepared on a computer[4].

Tench[4] adds that the first and most straightforward option is to leave spaces for the IPA text in the document and then print it and write the IPA symbols in by hand; but this method is awkward and time-consuming, and produces very unattractive results. He also explains that the second option is to use appropriate typefaces and fonts in a document that include the IPA symbols. This latter method produces very attractive results and is potentially very efficient, but it does require special fonts in most cases, and actually typing the IPA symbols can be rather slow, since many of them are not directly accessible from a computer keyboard and must be typed in special ways. 


\section{CONCLUSION}

Phonics as an EFL literacy instruction in ELT has strong educational significance. Yet, EFL teachers are often reluctant to use phonetic transcription because they are unfamiliar with it. Additionally, the odd appearance of the IPA makes it seem complicated to them. However, the IPA is very easy to learn and in many situations the use of phonetic transcription can save time and facilitate the teaching of concepts related to the spoken language. If we have not previously used phonetic transcription, it takes only a few hours to learn the IPA and a few more to understand the basic concepts, which we will rapidly gain back as time and energy saved in teaching our students.

Looking at the significance, the researcher sees the possibilities of its use in enhancing the foreign language teaching and learning (in this case English). Indeed, this paper is not intended to provide very deliberate references of how the phonetics transcription should be used by teachers or students. Nevertheless, it is a reminder that every piece of linguistics field might actually enhance teaching and learning process when used wisely and appropriately. Accordingly, after reviewing, analysing, and evaluating current literatures and research studies which are relevant to the issue, the researcher has come to an agreement that the phonetics transcription can serve as an effective EFL literacy instruction in ELT.

Last but not least, as a teacher, the researcher encourage himself as well as others in a similar profession, to develop our creativity and willingness in learning and applying the phonetics transcription as an EFL literacy instruction in ELT in order to enhance our professionalism.

\section{REFERENCES}

[1] Olugbeko, S. O. (2016). Phonic method: a strategy towards enhancing learning retention in basic literacy programme of Ondo State, Nigeria". International Journal of Education and Research, Vol 4(6), p.143-152.

https://www.ijern.com/journal/2016/June2016/11.pdf

[2] Pennington, M. C. \& Revell, P.R. (2019). English pronunciation teaching and research contemporary perspectives. London: Palgrave Macmillan. https://doi.org/10.1057/978-1-137-47677-7

[3] Hosseinzadeh, N. M., Kambuziya, A. K. Z. \& Shariati, M. (2015). British and American phonetic varieties. Journal of Language Teaching and Research, Vol, 6(3), p.647-655.

http://dx.doi.org/10.17507/jltr.0603.23

[4] Tench, P. (2011). Transcribing the sound of english: a phonetics workbook for words and discourse. Cambridge: Cambridge University Press. https://doi.org/10.1017/CBO9780511698361

[5] Wells, J. C. (2016). Sounds fascinating: further observations on english phonetics and phonology. Cambridge: Cambridge University Press. https://doi.org/10.1017/CBO9781316662342

[6] Fromkin, V., Rodman, R., \& Hyams, N. (2011). An introduction to language. Wadsworth: Cengage Learning.

[7] Stabler, E. (2012). Introduction to linguistics. Campbell.

https://www.scribd.com/doc/93018191/Linguis tics-Lecture-Notes-Edward-Stabler

[8] Thaen-nga, A. \& Leenam, W. (2016). The use of phonics instruction to enhance students' reading ability: a case study of grade 3 students at nam yuen school, nam yuen district, ubon ratchathani province. International Journal of ResearchGranthaalayah, Vol. 4(10), p.65-71.

http://oaji.net/articles/2016/13301479545531.pdf

[9] Gilakjani, A. P. (2011). A study on the situation of pronunciation instruction in ESL/EFL classrooms. Journal of Studies in Education, Vol. 1(1), p.1-15.

http://www.macrothink.org/journal/index.php/ jse/article/download/924/746 